\title{
Communicating Climate Change Risk: A Content Analysis of IPCC's Summary for Policymakers
}

\author{
P. Marijn Poortvliet ${ }^{1, *} \mathbb{C}$, Meredith T. Niles ${ }^{2}$, Jeroen A. Veraart ${ }^{3}{ }^{\circledR}$, Saskia E. Werners ${ }^{3,4}$, \\ Fiona C. Korporaal ${ }^{1}$ and Bob C. Mulder ${ }^{1}$ \\ 1 Strategic Communication Group, Wageningen University, 6700 EW Wageningen, The Netherlands; \\ fiona.korporaal@wur.nl (F.C.K.); bob.mulder@wur.nl (B.C.M.) \\ 2 Department of Nutrition and Food Sciences \& Food Systems Program, University of Vermont, Burlington, \\ VT 05405, USA; mtniles@uvm.edu \\ 3 Wageningen Environmental Research, 6700 AA Wageningen, The Netherlands; \\ jeroen.veraart@wur.nl (J.A.V.); saskia.werners@wur.nl (S.E.W.) \\ 4 Water Systems and Global Change Group, Wageningen University, 6700 AA Wageningen, The Netherlands \\ * Correspondence: marijn.poortvliet@wur.nl
}

Received: 13 May 2020; Accepted: 12 June 2020; Published: 15 June 2020

\begin{abstract}
This study investigated the effectiveness of climate change risk communication in terms of its theoretical potential to stimulate recipients' awareness and behavioral change. We selected the summary for policy makers (SPM) of the most recent Intergovernmental Panel on Climate Change (IPCC) report in order to conduct a content analysis; the extended parallel process model and construal level theory served as conceptual lenses to perform the analysis. Specifically, we evaluated to what extent the SPM included informational elements of threat, efficacy and psychological distance related to climate change. The results showed that threat information was prominently present, but efficacy information was less frequently included, and when it was, more often in the latter parts of the SPM. With respect to construal level it was found that in the IPCC report concrete representations were used only sparingly. Theoretical relevance and implications for climate change risk communication with key audiences are discussed.
\end{abstract}

Keywords: climate change; risk communication; psychological distance; threat appraisal; efficacy; global warming; content analysis

\section{Introduction}

A key challenge faced by humankind is climate change and its manifestations. According to the Intergovernmental Panel on Climate Change (IPCC) [1], the ways in which societal and environmental systems can mitigate and adapt to climate change will directly influence the magnitude of impacts. Among the greatest risks of climate change are the dangers it poses to civilization and its potential to be an important driver for natural disasters, droughts, poverty, famine, food and nutritional insecurity, and global health problems. According to the World Bank, insufficient reduction of greenhouse gas emissions (mitigation) will lead to rising net annual costs to manage climate related risks while global temperatures still increase [2]. As such, there is a strong need for both climate change mitigation to slow these impacts, and adaptation to changes already slated regardless of future mitigation to minimize detrimental and direct consequences for human survival [2,3]. However, communicating about these issues is challenging, and effective climate communication depends on how the message is designed, and how it resonates with the intended audience. Therefore, in this contribution, we study the effectiveness of climate change risk communication to stimulate recipients' awareness and behavioral change. 
A large majority of the scientific climate community agrees that climate change is a reality and needs adequate action [4], yet the United Nations Framework Convention on Climate Change in Paris (i.e., COP 21, 2015) exemplifies that this consensus only sluggishly translates into multilateral agreements. Although the accord was presented as a binding treaty, its policy implementation is constrained by unknown funding sources and the volatile political agendas of national governments. Further, the general public in many regions are still highly divided with regard to the sense of urgency of taking climate change action [5,6], though this sense of urgency is increasing [7]. This apparent disconnect in perceived urgency between experts and scientists on the one hand and policy makers and citizens on the other hand is referred to as the consensus gap [8].

In order to address this gap, it is important that key audiences-including the general public and policy makers-develop climate change risk perceptions that support educated decisions, adaptive behaviors and policies for climate change mitigation and adaptation [9-11]. Still, risk communication about climate change has proven to be notoriously difficult [6], in part because evidence suggests that this consensus gap is not primarily driven by a lack of understanding of knowledge about climate change. In other words, the concept of a "deficit model", which poses that people just do not understand climate change and thus more information will make them to believe the phenomenon, support policies and change behavior, has been falsified [12]. Instead, other research suggests that risk perceptions and perceived capacity to act are important drivers of mitigation and adaptation behaviors [13]. Supporting and creating public engagement and sustained behavior change is thus a vital strategy in closing the present-day consensus gap.

In this paper, we analyze the presumably most prominent climate change risk communication aimed at policy makers: The summary for policy makers (SPM) of IPCC's latest synthesis report [14]. The IPCC is the leading international body for the assessment of climate change. IPCC reviews and assesses the most recent socio-economic, technical and scientific information relevant to the understanding of climate change. To achieve the institution's aim, the IPCC must communicate their findings effectively to various interest groups such as policymakers, the media and the public [15]. The reports are published in three volumes—each written by a working group —and cover up-to-date knowledge concerning climate change (e.g., the causes, possible impacts and adaptation strategies). The IPCC reports are widely used as references in the scientific community, and have been cited in many research articles. The SPM is the most accessible of all IPCC reports, tailored to policymakers and aimed at providing a clear overview of the conclusions of each full IPCC working group report. Besides governments and policy makers at all levels, other parties such as non-governmental organizations, businesses and the wider public are also reached $[15,16]$. Analyzing how climate change information is represented is crucial given the fact that the next IPCC report is currently being written and planned for publication in 2022, and IPCC is also reconsidering its communication strategy [17].

We will investigate the SPM through the lens of two complementary behavioral theories-the extended parallel process model (EPPM) and construal level theory (CLT)—that both have a track record for identifying functional elements of risk communication [18-21]. By utilizing these two social psychological theories, the goal of this paper is to identify entry points that may help to increase the effectiveness of climate change risk communication. In this context, we define effective risk communication as communication that guides policymakers to design and establish policy, and that fosters awareness and behavioral change within the general public. We first discuss the challenges of communicating climate change, then introduce the EPPM and CLT frameworks, and finally present our analysis and discussion.

\subsection{Climate Risk Communications by IPCC}

Skepticism concerning climate change has grown in recent years despite the exponentially growing knowledge base and support from the scientific community [15,22-25]. Public opinion surveys regarding the reality of climate change show belief in its human causes reached lows in the US, the UK, Australia and The Netherlands around the end of 2009 [5,26-29]. Results from US-based 
studies showed that (segments of) citizens are still unconvinced about scientific claims related to causes of climate change and also that a sizeable portion of the public tends to be unaware of the prevalent consensus in the scientific climate community regarding these issues [23,30-32], and only a small proportion of EU citizens acknowledge that climate change required collective action [33]. Overall, public surveys indicate that there is confusion, complacency and denial amidst policymakers, the media and the public [15].

A number of characteristics of climate change itself may hamper effective communication [34], like its collective action nature [35,36], and the politicization around climate change and its institutionalization [37-39]. Other barriers stem from the complications of effectively communicating risks in order to create risk perceptions that actually affect behaviors. One reason is because risks are socially constructed [40]. People perceive the seriousness of a risk differently depending on where and when they live as well as their past experiences [41], and how much it matters or impacts their daily living, such as for farmers [42]. Of course, without awareness of the risks, self-protective action is not likely [43]. However, should these risks be communicated as particularly severe and affecting those confronted, then this might increase the chance of people trying to control their fear rather than taking action on the source of the hazard. The extended parallel processing model (EPPM) [44] explains how this works and makes clear how important it is to combine the communication of the risks with offering avenues how to solve them.

While past experiences with a climate change related event may help solidify climate beliefs and actions, this is complicated by uncertain projections of how the climate will change [45]. This has implications for the psychological distance that the message creates. The uncertain nature of climate change can make the subject of climate change more or less tangible to the receivers of risk communication. When risks are perceived as more distant, then this could lead to downplaying the risk. Construal level theory (CLT), articulated by Trope and Liberman [46], elaborates further on the effectiveness of communicating in either abstract or concrete modes. Both the EPPM and CLT are now further introduced below.

\subsection{Extended Parallel Process Model}

The EPPM predicts individual self-protective behavior on the basis of four concepts: susceptibility, severity, response efficacy and self-efficacy [44]. Within the current context of interest, susceptibility is the perception of the individual of how likely it is that they will be impacted by climate change. If an individual for instance lives in a high-risk area, their susceptibility will expectedly be high. Secondly, severity is the individual's perception on the magnitude of events caused by climate change. People will deem the severity as higher when, for example, a flood will destroy their property than when they only get their feet wet. Thirdly, response efficacy is the perception that a recommended action will successfully control climate change. The perceived actions should be seen as an effective manner to address climate change. If the actions are perceived as useless, response efficacy will be low. Lastly, self-efficacy is the extent to which the individual believes to have the ability to control the risk; in case of climate change, people have to believe in their own capabilities of executing the suggested actions to address (adapt to or mitigate) climate change impacts.

EPPM predicts three possible outcomes driven by these perceptions: danger control, fear control or no response at all [44]. Danger control occurs when the perceived threat-resulting from susceptibility and severity —and the perceived efficacy—resulting from response efficacy and self-efficacy—are high. If people see the risk as a real threat and they believe that they can take action to address the risk, they will accept the risk message and be motivated to control the impending danger. Fear control occurs when people perceive low efficacy. They will experience fear and to control this feeling they reject the risk message. Psychologically, people will control their fear by denying, avoiding or resisting the risk [47]. In the case of climate change, denial may occur due to the costs of taking action are extensive and its outcomes uncertain [34]. Finally, a no response scenario will occur if the perceived threat is low, as in this case no danger is perceived by the individual. The EPPM illustrates the need for 
effective risk communication which aims to clearly communicate the extent of the threat as well as people's ability to counteract the danger imposed on them to avoid denial or dismissal of the message.

The EPPM is a proven framework in the context of environmental perceptions and behaviors [48,49] and we will adopt it to study the SPM, as it allows for an analysis of key components of risk perception and predicts what type of action is likely to follow. However, in communicating risk the different responses to a risk do not only depend on the perceived threat and perceived efficacy; these will further depend on the level of concreteness of a risk message, which is specified in construal level theory.

\subsection{Construal Level Theory}

CLT [46] is used to further analyze how climate change risks are communicated. The appraisal of threat is not the only factor that causes people to avoid engaging in danger control; according to the CLT, whether or not people perceive a risk to be relevant for them personally is also an important factor, and, as such, may boost the recipient's perceptions of threat. The theory therefore builds logically upon the concepts of susceptibility and severity within the EPPM, and addresses why one should or should not be concerned with the threat.

According to the CLT, two levels of mental construal-the interpretation of an object or event-can be distinguished: high-level and low-level. High-level construal indicates more abstract thinking whereas the low-level construal indicates more concrete thinking [46]. According to the CLT, events that are interpreted as more psychologically distant are construed at a higher level, and those perceived closer are construed at a lower level. Four dimensions determine psychological distance. The first is temporal distance: further distance in time (and thus more abstract) would be either future or past, while a closer distance (thus more concrete) would be the present. The second is spatial distance: greater distance would be elsewhere (abstract), while a closer distance would be here (concrete). Third is social distance or the distance between social groups or individuals: further social distance (abstract) would be for instance when the threat is communicated to be affecting 'others', while a close social distance would be perceived as affecting the self or like oneself (concrete). The last dimension is hypothetical distance (also called the uncertainty dimension), or the likelihood of an event taking place: further hypothetical distance (abstract) would entail that there is a small chance of an event occurring, while a small psychological distance (concrete) would be a high likelihood of the event occurring.

Communicating and perceiving more concretely will lead to lower-level thinking and a stronger risk perception, because lower-level construal creates a more direct experience of the message. For instance, research found that risk communication that included concrete message elements were more effective in terms of recipients' awareness and preparation [50]. Likewise, a person having a direct experience with a hazard may have a profound impact on the formation of risk perceptions [51,52], which may lead to more engagement [46].

\subsection{The Present Research}

The overall aim of this research is to evaluate the effectiveness of communicating climate change in terms of their theoretical potential to stimulate awareness and behavioral change of recipients. This evaluation is based on a content analysis of the SPM of the latest IPCC synthesis report. Specifically, guided by EPPM and CLT, we seek to answer our research question: to what extent and how does the SPM include elements of threat, efficacy and psychological distance in presenting information about climate change?

\section{Materials and Methods}

A content analysis was conducted on IPCC's AR5 Summary for Policy Makers. This report has a length of 32 pages and 10,549 words. The SPM follows the structure of the more comprehensive report [14] which addresses the following topics: (1) Observed changes and their causes; (2) Future climate change, risks and impacts; (3) Future pathways for adaptation, mitigation and sustainable development; and (4) Adaptation and mitigation. We refer to these (numbered) sections as SPM 1-4. 
This analysis was performed by coding the text of the report, using the concepts from EPPM and the dimensions of CLT as codes; as such, we performed a directed content analysis on the SPM [53]. Sentences or text segments that were identified as addressing a concept from one of those theories were labelled with one (or more) codes. EPPM and CLT were thus independently used as coding schemes, and codes were developed by the authors. After coding, it was counted how many times each code was used, resulting in a total frequency for each concept. The timing or section of the use of each code was also noted as to find out when different concepts were used within the SPM [54]. Thus, the analysis was deductive and quantitative, meaning that there was no aim of identifying additional concepts or relationships between concepts [55], and focused on the frequency and timing of concepts in the report.

During preliminary coding, the challenges of coding concepts from EPPM and CLT emerged. Specifically, as mentioned in the introduction, EPPM encompasses the perceptions of threat and efficacy. That is, ultimately, the psychological appraisal of EPPM elements will determine its effectiveness. As we have no data on actual perceptions (i.e., responses to the messages), during coding it was at times not feasible to distinguish between severity and susceptibility elements, nor between response efficacy and self-efficacy; it was thus necessary to establish revised coding categories [56]. Therefore, we merged the severity and susceptibility codes into one threat code and likewise we merged response efficacy and self-efficacy into one efficacy code. Furthermore, it was similarly complex at points to distinguish between the four elements that make up CLT. Most notably, the spatial and the social dimensions often overlapped, and so did the temporal and hypothetical dimensions. We therefore utilized one unified spatial-social distance code (divided into abstract and concrete codes) and one unified temporal-hypothetical distance code (divided into abstract and concrete codes). For the dimensions of CLT (spatial-social distance and temporal-hypothetical distance), counts of abstract and concrete messages were made.

The report of the SPM was analyzed in ATLAS.ti and two researchers (P.M.P. and B.C.M.) with a background in social psychology and expertise in CLT and EPPM independently coded the content of the document. Few differences in coding emerged, and these were resolved and converged by discussion between the two researchers after each independent coding. Codes were used to label all occurrences of the theoretical concepts of interest throughout the text, after which frequencies could be calculated and qualitative observations could be made. So, the aim was to determine if, and to what extent, threat and efficacy messages were present, as well as to examine how they were applied (i.e., in abstract or concrete ways).

\section{Results}

We first present the two categories of EPPM, followed by an overview related to the CLT dimensions; specific examples from the policy report are offered for both EPPM and CLT. Figure 1 displays frequency of use of the concepts in the SPM report. 


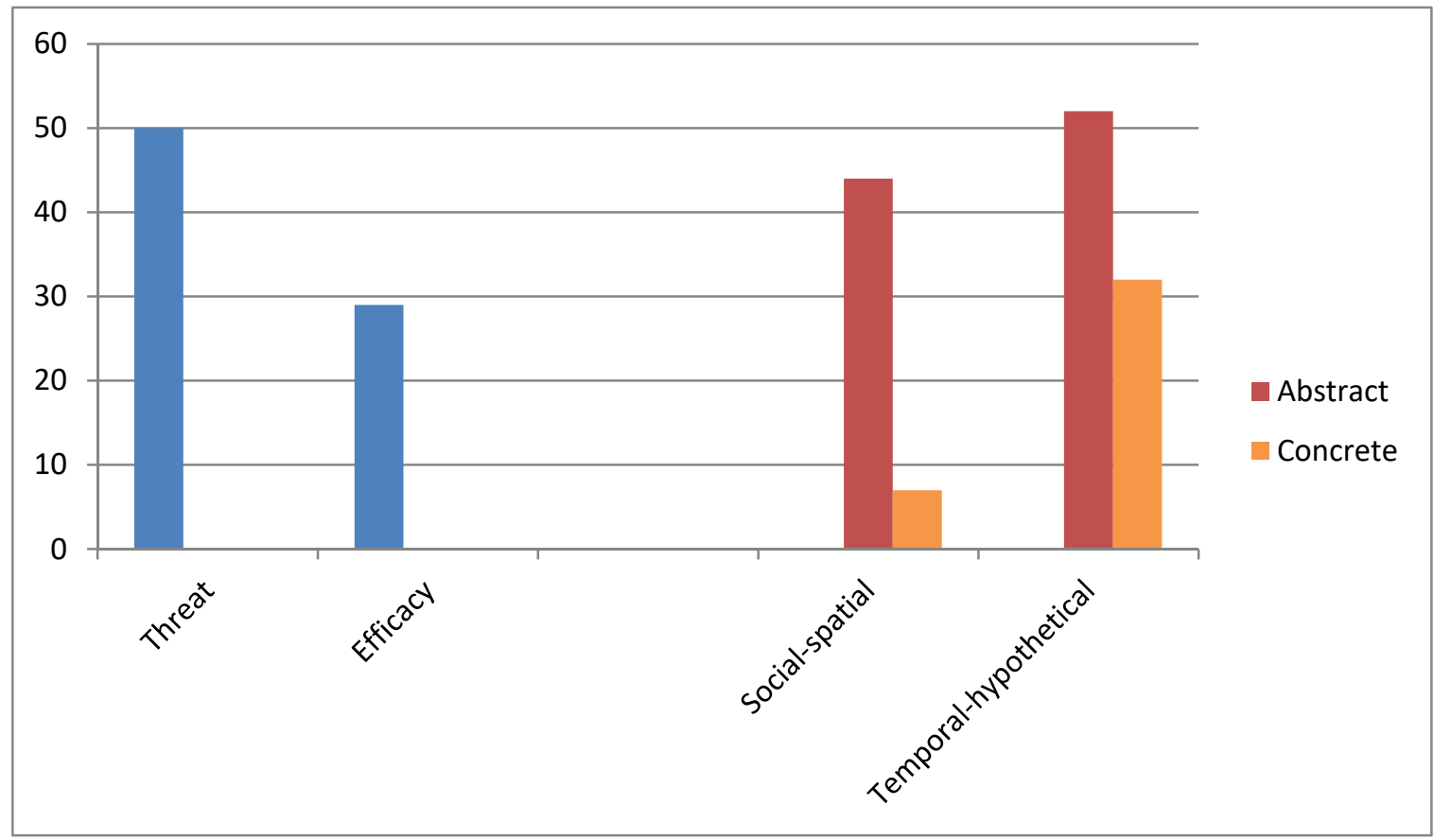

Figure 1. Frequencies of extended parallel process model (EPPM) concepts (left panel) and construal level theory (CLT) dimensions (right panel) observed in the summary for policy makers (SPM). CLT dimensions are divided into abstract and concrete messages.

\subsection{Threat}

In total, threat-related passages were coded 50 times throughout the SPM report; most frequently in the first two sections of the SPM (SPM 1: 17 counts; SPM 2: 25 counts), and less frequently in the last two sections (SPM 3: 7 counts; SPM 4: 1 count). The IPCC provides many examples of risks related to climate change, with the emphasis on extreme weather, such as heat waves and extreme precipitation, melting ice sheets and sea-level rise. An example of a passage reads: "Evidence of observed climate change impacts is strongest and most comprehensive for natural systems. In many regions, changing precipitation or melting snow and ice are altering hydrological systems, affecting water resources in terms of quantity and quality (... ). Assessment of many studies covering a wide range of regions and crops shows that negative impacts of climate change on crop yields have been more common than positive impacts" (page 6).

Furthermore, the report provides ample information concerning risk-affected areas, global risks, and timescales on which changes and risks are taking place. An example is "There are likely more land regions where the number of heavy precipitation events has increased than where it has decreased. Recent detection of increasing trends in extreme precipitation and discharge in some catchments implies greater risks of flooding at regional scale (... ). It is likely that extreme sea levels (for example, as experienced in storm surges) have increased since 1970, being mainly a result of rising mean sea level" (page 8).

The SPM discusses both changes in the climate system (Section 2.2) and future impacts for human life (Section 2.3). Various impacts are specified, notably threats to crop yields and food security, water resources, and economies and assets. It is noted that these impacts may have strong, globally destabilizing effects, because risks are unevenly distributed such that they are greater for disadvantaged people and communities. This, in turn, may lead to displacement of large groups of people, as well as conflicts and war. 


\subsection{Efficacy}

We coded 29 sections in the SPM as efficacy. The SPM is divided in four major parts. The first two discuss primarily the nature and technical background of the CC problem, while the latter two are about possible adaptation and mitigation. It is therefore not surprising that efficacy counts are almost absent in the first half of the report (SPM 1: 0 counts; SPM 2: 5 counts) and most dominant in the second part of it (SPM 3: 13 counts; SPM 4: 11 counts). Some representative sections read: "Adaptation and mitigation are complementary strategies for reducing and managing the risks of climate change. Substantial emissions reductions over the next few decades can reduce climate risks in the 21st century and beyond, increase prospects for effective adaptation, reduce the costs and challenges of mitigation in the longer term and contribute to climate-resilient pathways for sustainable development" (page 17); "Substantial cuts in GHG [green house gas] emissions over the next few decades can substantially reduce risks of climate change by limiting warming in the second half of the 21st century and beyond" (page 19); and "Behavior, lifestyle and culture have a considerable influence on energy use and associated emissions, with high mitigation potential in some sectors, in particular when complementing technological and structural change (medium evidence, medium agreement). Emissions can be substantially lowered through changes in consumption patterns, adoption of energy savings measures, dietary change and reduction in food wastes" (page 29).

Terms such as adaption and mitigation are used extensively throughout the report to illustrate that action can be undertaken to counter climate change related risks. Moreover, page 27 of the SPM includes a table that provides a comprehensive overview of solutions including those in disaster risk management, land-use planning and institutional arrangements. However, at the same time the efficacy of adaptation and mitigation strategies is questioned at various points in the SPM. For example, in Section 2.4 ('Climate change beyond 2100, irreversibility and abrupt changes') it is stated that "Many aspects of climate change and associated impacts will continue for centuries, even if anthropogenic emissions of greenhouse gases are stopped." (page 16). This suggests that although mitigation is possible, such actions may not prevent irreversible impacts in the long-term. On the same page, an interesting exception is mentioned: "except in the case of a large net removal of $\mathrm{CO}_{2}$ from the atmosphere over a sustained period."

In part 3 (Future Pathways for Adaptation, Mitigation and Sustainable Development), there appears to be a mix of messages that on the one hand convey that mitigation and adaptation have good efficacy, and on the other hand reveal that efficacy of any measure is limited, partly due to implementation problems. In addition, the high costs of mitigation and adaptation are mentioned several times. Overall, the emphasis is on the general response of limiting GHG emissions instead of on specific responses, such as behavior change strategies or the development and use of technology. All mitigation and adaptation strategies require climate policies that, according to the SPM, need coordinated cooperation at all national and international levels.

\subsection{Temporal-Hypothetical Dimension}

The second part of the analysis looked at the extent to which CLT concepts were used. Throughout the SPM, we find references to temporal and hypothetical aspects of climate change. In total, we counted 52 abstract codes and 32 concrete codes pertaining to this dimension. Oftentimes, passages in the report refer to climate change in term of large time windows, very future events, and instances in which there was a relatively high level of uncertainty: "Since the beginning of the industrial era, oceanic uptake of $\mathrm{CO}_{2}$ has resulted in acidification of the ocean" (page 4); "The rate of sea level rise since the mid-19th century has been larger than the mean rate during the previous two millennia" (page 4); "intensifying competition for water among sectors (limited evidence, medium agreement)" (page 13); "but global economic impacts from climate change are currently difficult to estimate" (page 16); and "warming is more likely than not to exceed $4^{\circ} \mathrm{C}$ above pre-industrial levels" (page 19).

At other points these mentions were (much) more concrete in terms of the temporal and hypothetical dimension: "recent anthropogenic emissions of green-house gases are the highest in history" (page 2); 
"A reduction in permafrost extent is virtually certain with continued rise in global temperatures" (page 16); and "Adaptation is place- and context-specific (high confidence)" (page 19).

\subsection{Social-Spatial Dimension}

Throughout the SPM, many references were made to social and spatial aspects of climate change. In total, there were 44 counts of abstract social-spatial dimension codes, with most being generic: "Recent climate changes have had widespread impacts on human and natural systems" (page 2); "Anthropogenic forcings have likely made a substantial contribution to surface temperature increases since the mid-20th century over every continental region except Antarctica" (page 5); "in many regions" (page 10); or "most land areas" (page 10). Sometimes, the level of precision is higher but even then the spatial representation remains rather broad: "Climate change is projected to reduce renewable surface water and groundwater resources in most dry subtropical regions" (page 13).

In contrast, only seven instances of concrete social-spatial dimension codes were observed. Examples include: "A nearly ice-free Arctic Ocean" (page 12); "Adaptation is place- and context-specific" (page 19); and "Some risks are particularly relevant for individual regions (Figure SPM.8)", in which the figure represents key risks for specific regions/continents (pages 13-14).

\section{Discussion}

This study set out to investigate how climate change risk communication was represented in the most recent SPM of the IPCC's AR5 report. Guided by two complementary theoretical frameworks we looked at the extent to which threat and efficacy information were present, and whether abstract and concrete messages were used. To the best of our knowledge, this is the first time that this methodology has been used to analyze the IPCC's representation of climate change risk communication.

\subsection{Occurrence of Threat and Efficacy Messages}

The results show a mixed picture when it comes to threat and efficacy information. First, we found that threat information (i.e., susceptibility and severity information) occurred more frequently than efficacy information (i.e., response efficacy and self-efficacy information). We also observed differences in timing: efficacy information was far more likely towards the end of the SPM report. This might seem a logical order in designing risk communication, but presenting threat and efficacy information jointly will likely be more effective because if people only read the first part of a report then they will only be exposed to fear appeals, but not to information that effectively provides risk-reducing behavioral options [44]. In addition, the undesirable defensive reaction towards threat information (i.e., fear control) may not be prevented if efficacy information is not presented in the same section.

As noted, climate change threats receive wide attention in SPM, but the communication of risks could be strengthened by (a) showing how the different risks are (causally) interrelated and thus (b) more explicitly showing how these diverse risks are relevant to human life. Furthermore, an important limitation of the IPCC work is that it is markedly technocratic and solidly grounded in natural science methods, which runs the risk of omitting perspectives of other relevant actors. For instance, with regard to risk information the IPCC focusses very much on 'golden standards' such as carbon concentrations and global temperatures, but this may alienate local communities because they might have different and, from their perspective, more tangible concerns [57-59], such as (extreme) weather events, effects on land use or detrimental health effects.

Successful examples with regard to adaptation and mitigation are a way to communicate efficacy; however, the SPM does not mention successful examples of countries or measures in the field of climate adaptation or mitigation. Instead, the SPM focuses on the measures that are yet to be taken in the future and considers its effectiveness and feasibility only in generic terms. This omission of concrete examples may be a conscious choice as policy makers were involved in the formulation of the SPM [17]. If you give an example, other countries might also want to be mentioned in the SPM. In the underlying full IPCC working group reports, successful and less successful examples of adaptation and mitigation 
are discussed; however, these reports are not written with the objective to communicate risk with the general public. In the SPM, responses to climate change are discussed under the headers of mitigation and adaptation. The discussion of concrete response options is rather limited, with the main focus of mitigation being on the reduction of GHG emissions, without significant detail on actualization. Obviously, we are conscious that the SPM is a summary of three assessment reports (each report has 700 to 1000 pages), and the underlying reports of the SPM were not analyzed. We observed that this type of knowledge does not recur in the summary.

The main advice is to develop climate policies through cooperation and coordination at all national and international levels. However, the efficacy of responses is offset with arguments that the efficacy of mitigation and adaptions efforts is limited or even rather low, the implementation thereof can be problematic and costs can be considerable. This seems to undermine the message that something can and should be done about climate change, right now, and at all costs (cf., [60]). As such, hazard information should be consistently combined with efficacy information [52,61]. We therefore argue that mitigation and adaptation responses could be made more effective by a) offering more concrete options and examples thereof and b) more strongly emphasizing the efficacy of those responses, while paying less attention to possible low efficacy and/or implementation issues (as these are also of hypothetical nature). All in all, we believe these recommendations should be taken into account in future climate change reporting, especially in IPCC's 6th assessment report which is planned for 2022.

\subsection{Representations of Climate Risks: Abstract and Concrete Message Elements}

A striking observation was the ratio of abstract and concrete messages across the SPM report. The use of concrete representations was much less frequent in the SPM (Figure 1), especially for the social/spatial dimension (seven concrete counts, 44 abstract counts). Possible explanations for using such abstract examples and passages in the SPM include: (1) the nature of a global report, as a result of which the authors do not want to single out specific regions or social groups (obviously, more details are given in the full IPCC working group reports); (2) the authors might wish to be cautious and therefore prefer general rather than specific statements; (3) the authors mention to be careful not to make claims when there is not complete certainty, therefore they use wordings like virtually, certain, very likely, etc. (see [62] for a discussion on the challenges in communicating certainty); (4) broad time horizons because pinpointing specific time horizons might be scientifically difficult; (5) the IPCC SPM is, at its core, a summary and synthesize document, thereby yielding little more than the bigger picture (i.e., abstract climate information). Regarding time horizons, a concrete message might also mean that a chance is represented within a lifetime, not just a window of a few years. This means that a period of a number of decades could still be perceived by readers as concrete information [63].

From a risk communication point of view, this approach may lead to a relatively large psychological distance between the audience and the subject of climate change [41], which could lead to a weak persuasive potential of the climate change risk information. We posit that the differentiation between abstract and concrete messages is important, and it may help to understand how reports can have a greater impact, particularly on those outside the scientific climate community. Policymakers bring a variety of perspectives to the subject of climate change, and some of them may impede effective risk messages from climate scientists. In the context of the IPCC, such messaging may render the report too technical and abstract to translate into hands-on policy. In fact, an earlier analysis pointed out that IPCC's SPM stands out negatively by scoring low on readability, especially in comparison with regular scientific publications or mainstream newspaper reports [64]. It is not just an overkill of jargon that hampers the potential of the SPM, but also because it follows the formal and technocratic structure of the IPCC reports [65] resulting in overly abstract matter, which can be difficult to process by the reader.

There are ways to overcome these communicative issues. In case climate information is represented in abstract ways, this can be coupled to particular frames (e.g., an economic frame, an environmental frame) that will make it easier for recipients to relate to [66] (page 8). Research has demonstrated that reduced psychological distance benefits people's engagement on the issue of climate change [67-69], 
which would suggest that climate communication represented as psychologically close will lead to greater willingness to adopt mitigation behaviors and support mitigation policies; this is also in line with recent communication recommendations aiming for more concrete climate change communication [66].

Relatedly, it should be noted that many different climate change risks are identified through the SPM. However, risks are often described generally, or in terms of weather events (e.g., precipitation, extreme weather, heat waves). Another set of risks explicitly concern impacts relevant to humans that result from changes in weather patterns, such as impacts on food security, water resources and vector-borne diseases. More distal consequences from impacts on humans are also mentioned, albeit to a lesser extent, such as conflicts, displacement of people and threats to assets or economies. Moving from a focus on the hazards (such as weather) to the valued impacts could be a really important communication strategy (cf. [70]).

\subsection{Methodological Considerations}

Performing a content analysis on a report for policymakers was at times challenging. We deemed it necessary to collapse the four elements of the EPPM (susceptibility, severity, response efficacy and self-efficacy) into the two broader threat and efficacy categories, which is in the end conceptually in line with EPPM theory itself. Because the current research did not focus on the formation of perceptions but rather on analyzing the content of climate communication, we would recommend this relatively parsimonious way of coding in similar research.

Another point related to the use of the EPPM model merits discussion as well. Extant research suggests that risk perceptions are not solely defined by an individual's perception, but also contingent upon the political-economic context and culture within a nation, as well as different types of groups and individuals in society with variegated risk preferences [71,72]. We acknowledge that such political, cultural, economic and sociological dynamics may influence how people perceive risks, and future research could investigate these higher-level dynamics vis-à-vis individual processes in the formation of risk perceptions and risk behaviors [73].

With regard to the CLT, collapsing the four dimensions (social, spatial, temporal and hypothetical) into two broader dimensions turned out to be the most feasible option for the present research purpose, given the observed co-occurrence of the social and spatial dimension and the temporal and hypothetical dimensions, respectively. Thus, it is hard (or easy, depending on perspective) to use the CLT dimensions as codes. For instance, all future events are of hypothetical nature by definition.

\section{Conclusions}

This study set out to investigate the effectiveness of climate change risk communication. We showed that in in IPCC's SPM threat information was prominently present, but efficacy information was less often observed and when it was, more often in the latter part of the IPCC report. With respect to level of construal it was found that in the IPCC report relatively little use was made of concrete relative to abstract representations.

Given the complexity of both individual belief and risk perceptions, in combination with communication efforts, our results have several implications for climate change risk communication. First, we suggest that the overall goal of climate change communication should first be determined. If the aim is one of scientific communication versus a call to action for behavior change, varying communication messages may be most appropriate. Second, upon completion, we suggest that greater efforts towards measuring the efficacy of climate change risk communication could be utilized to track the effect of varying communication strategies quantitatively. Such efforts could be evaluated for their effectiveness and potentially adjusted based on continued research in this field.

Author Contributions: P.M.P. and B.C.M. were involved in study design, analyzed the data, and drafted the manuscript. M.T.N., J.A.V., S.E.W., and F.C.K. drafted the manuscript and critically reviewed the paper. All authors have read and agreed to the published version of the manuscript.

Funding: This research received no external funding. 
Acknowledgments: The authors thank Jessica Rietveld for providing input to earlier versions of this article, and also thank three anonymous reviewers for offering constructive comments.

Conflicts of Interest: The authors declare no conflict of interest.

\section{References}

1. IPCC. Part A: Global and Sectoral Aspects. Contribution of Working Group II to the Fifth Assessment Report of the Intergovernmental Panel on Climate Change. In Climate Change: Impacts, Adaptation, and Vulnerability; Cambridge University Press: Cambridge, UK; New York, NY, USA, 2014; p. 1132.

2. Hallegatte, S.; Bangalore, M.; Bonzanigo, L.; Fay, M.; Kane, T.; Narloch, U.; Rozenberg, J.; Treguer, D.; Vogt-Schilb, A. Shock Waves: Managing the Impacts of Climate Change on Poverty; World Bank: Washington, DC, USA, 2016.

3. European Commission. Climate Action: Climate Change Consequences. Available online: http://ec.europa. eu/clima/change/consequences/index_en.htm (accessed on 16 April 2015).

4. Oreskes, N. The scientific consensus on climate change. Science 2004, 306, 1686. [CrossRef]

5. Dewulf, A.; Boezeman, D.; Vink, M.J. Climate Change Communication in the Netherlands; Oxford University Press: Oxford, UK, 2017.

6. Moser, S.C. Communicating climate change: History, challenges, process and future directions. Wires Clim. Chang. 2010, 1, 31-53. [CrossRef]

7. Steentjes, K.; Pidgeon, N.F.; Poortinga, W.; Corner, A.J.; Arnold, A.; Böhm, G.; Mays, C.; Poumadère, M.; Ruddat, M.; Scheer, D.; et al. European Perceptions of Climate Change (EPCC): Topline Findings of a Survey Conducted in Four European Countries in 2016; Cardiff University: Cardiff, UK, 2017.

8. Cook, J.; Nuccitelli, D.; Green, S.A.; Richardson, M.; Winkler, B.; Painting, R.; Way, R.; Jacobs, P.; Skuce, A. Quantifying the consensus on anthropogenic global warming in the scientific literature. Environ. Res. Lett. 2013, 8, 024024. [CrossRef]

9. André, K.; Baird, J.; Swartling, Å.G.; Vulturius, G.; Plummer, R. Analysis of Swedish forest owners' information and knowledge-sharing networks for decision-making: Insights for climate change communication and adaptation. Environ. Manag. 2017, 59, 885-897. [CrossRef]

10. Haden, V.R.; Niles, M.T.; Lubell, M.; Perlman, J.; Jackson, L.E. Global and local concerns: What attitudes and beliefs motivate farmers to mitigate and adapt to climate change? PLoS ONE 2012, 7, e52882. [CrossRef] [PubMed]

11. Niles, M.T.; Lubell, M.; Haden, V.R. Perceptions and responses to climate policy risks among California farmers. Glob. Env. Chang. 2013, 23, 1752-1760. [CrossRef]

12. Pouliot, C.; Godbout, J. Thinking outside the 'knowledge deficit' box. Embo Rep. 2014, 15, 833-835. [CrossRef]

13. Niles, M.T.; Brown, M.; Dynes, R. Farmer's intended and actual adoption of climate change mitigation and adaptation strategies. Clim Chang. 2016, 135, 277-295. [CrossRef]

14. IPCC. Contribution of Working Groups I, II and III to the Fifth Assessment Report of the Intergovernmental Panel on Climate Change. In Climate Change 2014: Synthesis Report; Core Writing Team, Pachauri, R.K., Meyer, L.A., Eds.; IPCC: Geneva, Switzerland, 2014; p. 151.

15. Sterman, J.D. Communicating climate change risks in a skeptical world. Clim. Chang. 2011, 108, 811-826. [CrossRef]

16. IPCC. Communication Strategy. Available online: http://www.ipcc.ch/meetings/session35/IAC_ CommunicationStrategy.pdf (accessed on 11 April 2015).

17. Petersen, A.; Blackstock, J.; Morisetti, N. New leadership for a user-friendly IPCC. Nat. Clim. Chang. 2015, 5, 909-911. [CrossRef]

18. Goodall, C.E.; Reed, P. Threat and efficacy uncertainty in news coverage about bed bugs as unique predictors of information seeking and avoidance: An extension of the EPPM. Health Commun. 2013, 28, 63-71. [CrossRef] [PubMed]

19. Jung, T.; Brann, M. Analyzing the extended parallel process model and health belief model constructs in texting while driving: News coverage in leading U.S. news media outlets. Int. J. Health Promot. Educ. 2014, 52, 210-221. [CrossRef] 
20. Smith, S.W.; Rosenman, K.D.; Kotowski, M.R.; Glazer, E.; McFeters, C.; Keesecker, N.M.; Law, A. Using the EPPM to create and evaluate the effectiveness of brochures to increase the use of hearing protection in farmers and landscape workers. J. Appl. Commun. Res. 2008, 36, 200-218. [CrossRef]

21. Van der Linden, S. The social-psychological determinants of climate change risk perceptions: Towards a comprehensive model. J. Environ. Psychol. 2015, 41, 112-124. [CrossRef]

22. Ekwurzel, B.; Frumhoff, P.C.; McCarthy, J.J. Climate uncertainties and their discontents: Increasing the impact of assessments on public understanding of climate risks and choices. Clim. Chang. 2011, 108, 791-802. [CrossRef]

23. Leiserowitz, A.A.; Maibach, E.W.; Roser-Renouf, C.; Smith, N.; Dawson, E. Climategate, public opinion, and the loss of trust. Am. Behav. Sci. 2013, 57, 818-837. [CrossRef]

24. Scruggs, L.; Benegal, S. Declining public concern about climate change: Can we blame the great recession? Glob. Env. Chang. 2012, 22, 505-515. [CrossRef]

25. Weber, E.U.; Stern, P.C. Public Understanding of Climate Change in the United States; National Research Council, Columbia University: New York, NY, USA, 2011.

26. Hanson, F. Australia and the World: Public Opinion and Foreign Policy; Lowly Institute Poll 2009; Lowly Institute for International Policy: Sydney, Australia, 2009.

27. Moser, S.C.; Dilling, L. Communicating climate change: Closing the science-action gap. In The Oxford Handbook of Climate Change and Society; Oxford University Press: Oxford, UK, 2011; pp. 161-174.

28. Modest support for 'Cap and Trade' policy. In Fewer American See Solid Evidence of Global Warming; The Pew Research Center for People and The Press: Washington, DC, USA, 2009.

29. Riddell, P.; Webster, B. Widespread Skepticism on Climate Change Undermines Copenhagen Summit. The Times Online. 2009. Available online: http://timesonline.co.uk/tol/news/environment/article6916519.ece (accessed on 15 May 2015).

30. Gallup. One in Four in USA Are Solidly Skeptical of Global Warming. Available online: news.gallup.com/ poll/168620/one-four-solidly-skeptical-global-warming.aspx (accessed on 12 February 2018).

31. Lorenzoni, I.; Whitmarsh, L. Climate change and perceptions, behaviors, and communication research after the IPCC 5th Assessment Report-A WIREs Editorial. Wires Clim. Chang. 2014, 5, 703-708. [CrossRef]

32. YPCCC. Yale Climate Opinion Maps. 2018. Available online: https://climatecommunication. yale.edu/visualizations-data/ycom-us-2018/?est=happening\&type=value\&geo=county (accessed on 12 February 2018).

33. European Commission. Special Eurobarometer 435. Climate Change; Wave EB83.4; TNS Opinion \& Social, European Commission: Brussels, Belgium, 2015.

34. Ross, L.; Arrow, K.; Cialdini, R.; Diamond-Smith, N.; Diamond, J.; Dunne, J.; Ehrlich, P.; Feldman, M.; Horn, R.; Kennedy, D.; et al. The climate change challenge and barriers to the exercise of foresight intelligence. BioScience 2016, 66, 363-370. [CrossRef]

35. Steffen, W. A complex and diabolical policy problem. In The Oxford Handbook of Climate Change and Society; Oxford University Press: Oxford, UK, 2011; pp. 21-37.

36. Jamieson, D. The Nature of the Problem. In The Oxford Handbook of Climate Change and Society; Oxford University Press: Oxford, UK, 2011; pp. 38-54.

37. Dunlap, R.E.; McCright, A.M. Organized climate change denial. In The Oxford Handbook of Climate Change and Society; Oxford University Press: Oxford, UK, 2011; pp. 144-160.

38. Hajer, M.; Versteeg, W. Voices of Vulnerability. In The Oxford Handbook of Climate Change and Society; Oxford University Press: Oxford, UK, 2011; pp. 55-95.

39. Howe, P.; Mildenberger, M.; Marlon, J.; Leiserowitz, A. Geographic variation in opinions on climate change at state and local scales in the USA. Nat. Clim. Chang. 2015, 5, 596-603. [CrossRef]

40. Slovic, P. Trust, emotion, sex, politics, and science: Surveying the risk-assessment battlefield. Risk Anal. 1999, 19, 689-701. [CrossRef] [PubMed]

41. Zwickle, A.; Wilson, R.S. Construing risk. Implications for risk communication. In Effective Risk Communication; Árvai, J., Rivers, L., Eds.; Routledge: New York, NY, USA, 2014; pp. 190-203.

42. Niles, M.T.; Lubell, M.; Brown, M. How limiting factors drive agricultural adaptation to climate change. Agric. Ecosyst. Env. 2015, 200, 178-185. [CrossRef]

43. Leiserowitz, A.A. American risk perceptions: Is climate change dangerous? Risk Anal. 2005, 25, 1433-1442. [CrossRef] 
44. Witte, K. Putting the fear back into fear appeals: The extended parallel process model. Commun. Monogr. 1992, 59, 329-349. [CrossRef]

45. Van Pelt, S.C.; Haasnoot, M.; Arts, B.; Ludwig, F.; Swart, R.; Biesbroek, R. Communicating climate (change) uncertainties: Simulation games as boundary objects. Env. Sci. Policy 2015, 45, 41-52. [CrossRef]

46. Trope, Y.; Liberman, N. Construal-level theory of psychological distance. Psychol. Rev. 2010, 117, 440-463. [CrossRef] [PubMed]

47. Verroen, S.; Gutteling, J.M.; De Vries, P.W. Enhancing self-protective behavior: Efficacy beliefs and peer feedback in risk communication. Risk Anal. 2013, 33, 1252-1264. [CrossRef] [PubMed]

48. Gebrehiwot, T.; Van der Veen, A. Farmers prone to drought risk: Why some farmers undertake farm-level risk-reduction measures while others not? Environ. Manag. 2015, 55, 588-602. [CrossRef] [PubMed]

49. Le Dang, H.; Li, E.; Nuberg, I.; Bruwer, J. Farmers' perceived risks of climate change and influencing factors: A study in the Mekong Delta, Vietnam. Environ. Manag. 2014, 54, 331-345. [CrossRef]

50. Hicks, A.; Armijos, M.T.; Barclay, J.; Stone, J.; Robertson, R.; Cortés, G.P. Risk communication films: Process, product and potential for improving preparedness and behaviour change. Int. J. Disaster Risk Reduct. 2017, 23, 138-151. [CrossRef]

51. Brownlee, M.T.J.; Hallo, J.C.; Wright, B.A.; Moore, D.; Powell, R.B. Visiting a climate-influenced national park: The stability of climate change perceptions. Environ. Manag. 2013, 52, 1132-1148. [CrossRef]

52. Wachinger, G.; Renn, O.; Begg, C.; Kuhlicke, C. The risk perception paradox: Implications for governance and communication of natural hazards. Risk Anal. 2013, 33, 1049-1065. [CrossRef] [PubMed]

53. Hsieh, H.F.; Shannon, S.E. Three approaches to qualitative content analysis. Qual. Health Res. 2005, 15, 1277-1288. [CrossRef]

54. Holsti, O.R. Content Analysis for the Social Sciences and Humanities; Addison-Wesley: Reading, MA, USA, 1969.

55. Hennink, M.; Hutter, I.; Bailey, A. Qualitative Research Methods; Sage: Newbury Park, CA, USA, 2011.

56. Berg, B.L. Qualitative Research Methods for the Social Sciences; Allyn \& Bacon: Boston, MA, USA, 2009.

57. Bunyan, S.; Collins, A.; Duffy, D. Concern and helplessness: Citizens' assessments of individual and collective action on the provision of environmental public goods in a coastal city at risk of inundation. Environ. Manag. 2016, 58, 431-445. [CrossRef] [PubMed]

58. Turnhout, E.; Bloomfield, B.; Hulme, M.; Vogel, J.; Wynne, B. Conservation policy: Listen to the voices of experience. Nature 2012, 488, 454-455. [CrossRef] [PubMed]

59. Turnhout, E.; Dewulf, A.; Hulme, M. What does policy-relevant global environmental knowledge do? The cases of climate and biodiversity. Curr. Opin. Env. Sust. 2016, 18, 65-72. [CrossRef]

60. Neuwirth, K.; Dunwoody, S.; Griffin, R.J. Protection motivation and risk communication. Risk Anal. 2000, 20, 721-734. [CrossRef]

61. Bubeck, P.; Botzen, W.J.; Aerts, J.C. A review of risk perceptions and other factors that influence flood mitigation behavior. Risk Anal. 2012, 32, 1481-1495. [CrossRef]

62. Hollin, G.J.S.; Pearce, W. Tension between scientific certainty and meaning complicates communication of IPCC reports. Nat. Clim Chang. 2015, 5, 753-756. [CrossRef]

63. Henrich, L.; McClure, J.; Crozier, M. Effects of risk framing on earthquake risk perception: Life-time frequencies enhance recognition of the risk. Int. J. Disaster Risk Reduct. 2015, 13, 145-150. [CrossRef]

64. Barkemeyer, R.; Dessai, S.; Monge-Sanz, B.; Renzi, B.G.; Napolitano, G. Linguistic analysis of IPCC summaries for policymakers and associated coverage. Nat. Clim Chang. 2016, 6, 311. [CrossRef]

65. Black, R. No more summaries for wonks. Nat. Clim Chang. 2015, 5, 282-284. [CrossRef]

66. Corner, A.; Shaw, C.; Clarke, J. Principles for Effective Communication and Public Engagement on Climate Change: A Handbook for IPCC Authors; Climate Outreach: Oxford, UK, 2018.

67. Jones, C.; Hine, D.W.; Marks, A.D. The future is now: Reducing psychological distance to increase public engagement with climate change. Risk Anal. 2017, 37, 331-341. [CrossRef]

68. Lee, T.M.; Markowitz, E.M.; Howe, P.D.; Ko, C.Y.; Leiserowitz, A.A. Predictors of public climate change awareness and risk perception around the world. Nat. Clim Chang. 2015, 5, 1014-1020. [CrossRef]

69. Weber, E.U. Experience-based and description-based perceptions of long-term risk: Why global warming does not scare us (yet). Clim. Chang. 2006, 77, 103-120. [CrossRef]

70. Weaver, C.P.; Moss, R.H.; Ebi, K.L.; Gleick, P.H.; Stern, P.C.; Tebaldi, C.; Wilson, R.S.; Arvai, J.L. Reframing climate change assessments around risk: Recommendations for the US National Climate Assessment. Environ. Res. Lett. 2017, 12, 080201. [CrossRef] 
71. Chauvin, B. Individual differences in the judgment of risks: Sociodemographic characteristics, cultural orientation, and level of expertise. In Psychological Perspectives on Risk and Risk Analysis; Raue, M., Lermer, E., Streicher, B., Eds.; Springer: Cham, Switzerland, 2018; pp. 37-61.

72. Clahsen, S.C.; Van Kamp, I.; Hakkert, B.C.; Vermeire, T.G.; Piersma, A.H.; Lebret, E. Why do countries regulate environmental health risks differently? A theoretical perspective. Risk Anal. 2019, 39, 439-461. [CrossRef] [PubMed]

73. Engler, A.; Poortvliet, P.M.; Klerkx, L. Toward understanding conservation behavior in agriculture as a dynamic and mutually responsive process between individuals and the social system. J. Soil Water Conserv. 2019, 74, 74A-80A. [CrossRef]

(C) 2020 by the authors. Licensee MDPI, Basel, Switzerland. This article is an open access article distributed under the terms and conditions of the Creative Commons Attribution (CC BY) license (http://creativecommons.org/licenses/by/4.0/). 